\title{
Resistência e empoderamento na literatura urbana carioca
} Rôssi Alves ${ }^{1}$

A rua não é sua, eu não preciso prestar contas. Roverdose $^{2}$

A roda cultural é uma manifestação originada há cerca de seis anos na cidade do Rio de Janeiro e que deu origem ao coletivo Circuito Carioca de Ritmo e Poesia (CCRP). Esse coletivo organiza oito rodas espalhadas pela cidade, sendo sete no subúrbio carioca e uma na zona sul. A roda cultural é o encontro de artistas, como grafiteiros, MCs (mestres de cerimônia), poetas, fotógrafos, cantores, performers... Há em torno de 120 rodas culturais $^{3}$ que ocorrem diariamente, sempre em logradouros públicos, com participação aberta a todo e qualquer artista e de forma gratuita. ${ }^{4}$

Entre as inúmeras artes que a roda cultural reúne, a roda de rima e a batalha de rima são as que concentram maior número de pessoas em torno do evento. MCs fazem freestyle em pequenas rodas, como um jogo de rimas com os amigos, ou em batalhas de rima, disputadas em duplas. As duas formas mais comuns de freestyle são:

o improviso "desinteressado" das rodas de rima e o apresentado nos duelos das batalhas de rima. Esse contexto de elaboração poética produz significativa diferença no resultado da rima. $\mathrm{O}$ freestyle "desinteressado" é a rima de improviso criada em situação de descontração, cujo objetivo é construir uma poesia da qual emane emoção e mensagem. Há normalmente uma narrativa, pois partese, comumente, de um tema "proposto" pelo primeiro a rimar (a

\footnotetext{
${ }^{1}$ Doutora em letras e professora da Universidade Federal Fluminense (UFF), Niterói, RJ, Brasil. Email: rossialves14@gmail.com

${ }^{2}$ Verso da música "Vizinhança". Disponível em: <https://goo.gl/iOkJK1>.

${ }^{3}$ De acordo com os dados levantados pelo projeto "Arte de rua e resistência", desenvolvido pela autora deste artigo juntamente com estudantes do curso de Produção Cultural da Universidade Federal Fluminense (UFF), do Campus de Rio das Ostras. As informações estão disponíveis em: <www.artederuaeresistencia.com.br>. Acesso em: 2 jul. 2016.

${ }^{4}$ Dado que o tema em estudo aqui não possui, ainda, fontes bibliográficas variadas, e entendendo a internet como campo legítimo e abundante para o estudo da cultura urbana, este trabalho utilizar-seá de entrevistas feitas através da rede social Facebook, documentos públicos disponíveis em sites, declarações copiadas de perfis em redes sociais e vídeos disponíveis na plataforma Youtube. As entrevistas são realizadas com o propósito de melhor entendimento do campo de estudo, estando os entrevistados cientes de seu uso público.
} 
exceção dá-se quando o rimador faz seu freestyle sozinho, podendo "passear" por vários temas) e, numa socialização e respeito à roda de rimadores, mantém-se o tema, desenvolvendo-o. Essa rima é bastante devedora dos estímulos externos. Na ausência de um tema específico (ou mesmo sob a tutela deste), o rimador, liberto para criar, pode construir sua poesia em torno de fatos do cotidiano, temas abstratos, situações em curso. A rima criada por um MC em momento de batalha, embora se deseje emocionante e portadora de mensagem, nem sempre resulta nisso, dada a grande pressão que envolve o candidato, no momento da realização - curtíssimo tempo para elaboração da rima, tensão por participar de um duelo, expectativa da plateia, entre outros fatores (Alves, 2014).

E as rimas são pautadas pelo cotidiano da cidade e do país. Política, sexo, amor, arte, rep, ${ }^{5}$ entre outros temas, atravessam a poesia das ruas.

O rap no Rio de Janeiro assume a função de levar a consciência de raça e classe para a população preta pobre e marginalizada daquela cidade. Essa atitude, tanto em são Paulo como no Rio de Janeiro, propiciou que os grupos de rap mantivessem uma profunda ligação com ideais políticos e ideológicos do hip-hop nacional, que foram se afirmando aos poucos como a luta pelo fim do preconceito, do racismo, da violência policial e também o término das desigualdades sociais existentes nas periferias das cidades brasileiras, de onde a maioria desses grupos surgiu (Felix, 2005, p. 124).

Entretanto, mesmo mais afeito às temáticas políticas, o mais comum é que estas surjam nas batalhas de conhecimento e de ideias/temáticas. ${ }^{6}$ Como o público é quem pauta os assuntos, a diversidade é grande, mas há nítida preferência por palavras que encaminhem a rima para um discurso ideológico. Como os do MC Garcia apresentados numa edição da Batalha do Conhecimento, e reproduzidos no quadro 1 a seguir.

Excepcionalmente, há um palco, pois essa batalha faz parte de uma festa, a Tatoo Week. ${ }^{7}$ Muitas luzes no palco, muita gente na plateia. Por

\footnotetext{
${ }^{5}$ Opto pela forma "rep" em detrimento de "rap", tendo em vista ela assim ser preferida por muitos integrantes do movimento carioca e por considerá-la mais aderente ao formato que este movimento cultural adotou no Brasil - ativista, irreverente, preocupado em criar uma estética brasileira.

${ }^{6}$ Além das batalhas de conhecimento, há também batalhas de sangue, modalidade que consiste em pronunciar ofensas para ridicularizar o MC adversário.

${ }^{7}$ Mais informações sobre o evento estão disponíveis em: 〈http://goo.gl/d2Bw8r〉.
} 
ser uma batalha temática, há o quadro com dezenas de palavras selecionadas pelo público. No palco, estão os dois MCs que duelam, o DJ, o fotógrafo e o apresentador.

MC Garcia anda de um lado a outro do palco, por alguns segundos, esperando a batida rodar. Quando inicia a rima, segue para frente do quadro e aponta palavras - provavelmente as que está usando na sua poesia - e permanece alguns segundos ali, enquanto seu desafiante, MC Morcego, anda de um lado a outro do palco, parecendo despreocupado. O quadro 1 traz apenas fragmentos da produção do MC.

QUADRO 1 - Transcrição de rimas de MC Garcia durante a batalha do conhecimento na Tatoo Week (2015)

\begin{tabular}{|l|l|}
\hline \multicolumn{1}{|c|}{ Versos } & \multicolumn{1}{c|}{ Expressão corporal } \\
\hline Ah, irmão pode parar com isso. & $\begin{array}{l}\text { O MC anda de um lado a outro do palco, em direção } \\
\text { ao quadro e seu corpo balança no ritmo da batida. }\end{array}$ \\
\hline $\begin{array}{l}\text { Eu vou chegando aqui e mostrando meu } \\
\text { compromisso, }\end{array}$ & $\begin{array}{l}\text { O MC para em frente ao quadro, lê algumas } \\
\text { palavras. }\end{array}$ \\
\hline porque essa é minha pegada. & $\begin{array}{l}\text { Vira-se para a plateia e, em tom grave, profere os } \\
\text { versos a seguir. }\end{array}$ \\
\hline $\begin{array}{l}\text { Eu vim da roça e quem é da roça não tem } \\
\text { medo de pôr a mão enxada. }\end{array}$ & $\begin{array}{l}\text { A expressão facial revela seriedade. Ainda de frente } \\
\text { para a plateia, ele parece querer convencê-la de sua } \\
\text { mensagem. }\end{array}$ \\
\hline E é por isso que eu escancaro: & $\begin{array}{l}\text { Levanta o braço livre como se conclamando o } \\
\text { público. }\end{array}$ \\
\hline $\begin{array}{l}\text { quem é da favela, irmão, tem a mão cheia } \\
\text { de calo! }\end{array}$ & $\begin{array}{l}\text { A sua expressão facial unida à impostação da voz } \\
\text { denotam, através deste verso, orgulho de ser } \\
\text { trabalhador. Alguns da plateia gritam e levantam os } \\
\text { braços em sinal de apoio à rima apresentada. }\end{array}$ \\
\hline
\end{tabular}

A construção textual proposta pelo MC no momento da batalha advém de um derramamento de emoções. Bakhtin (1997, p. 33) aponta que "o próprio signo e todos os seus efeitos (todas as ações, reações e novos signos que ele gera no meio social circundante) aparecem na experiência exterior". A exposição das palavras e a expressão corporal produzem o texto do MC. E essa estruturação dá maior vigor à rima. A palavra, como símbolo ideológico, possui um significado fora dela e a soma desses fatores corrobora para $\mathrm{o}$ sucesso das rimas nas batalhas.

Apropriando-se das palavras "compromisso", "enxada" e "calo", o $\mathrm{MC}$, nesse curto trecho, constrói um "texto" em que registra o lugar de onde fala: é uma pessoa que não se assusta com desafios e que tem orgulho de enfrentar as adversidades com firmeza. O MC esclarece que 
este é seu "compromisso" - e de todos que vêm de comunidades: destemor para a luta/trabalho e para alardear essa disposição.

As batalhas são formadas por dois rounds - cada um com 45 segundos. Contudo, nessa batalha, os dois MCs saíram-se tão bem nos dois primeiros rounds, que o público pediu um terceiro round para desempatar.

É comum que as batalhas de conhecimento é temáticas contem com um quadro no qual são escritas as palavras que os MCs têm de usar nas rimas. Se não houver um quadro com os temas, tudo pode caber na rima do poeta. Há sempre outros estímulos, como o cenário das ruas, uma roupa, uma pessoa, um cheiro, som, uma situação inusitada, um letreiro luminoso... $\mathrm{Na}$ elaboração poética a seguir, o $\mathrm{MC}$, para introduzir a argumentação política, faz uso da "manipulação do dado linguístico" que, segundo Zumthor, "contribui para provocar ou reforçar a rima, a aliteração, os ecos sonoros de toda espécie ou, de modo mais geral, acusa a escansão dos ritmos [...]. Em último caso, a frase, as próprias palavras se apagam em concatenações desprovidas de significação codificada, puras sugestões sonoras" (2010, p. 156).

É uma batalha temática, no saguão do Museu de Arte do Rio. Não há palco, o público dentro do museu é numeroso, outras pessoas amontoam-se na calçada, de onde é possível assistir à batalha através das paredes de vidro. O apresentador é MC Marechal, respeitado e com um fã-clube extenso. O tema da batalha final é "Amarildo". 8 MC Lodk é o primeiro a rimar, e o exemplo que segue no quadro 2 é um pequeno trecho da produção do rimador. A pressão sobre os MCs é grande, porque não há suficiente distância entre eles e a plateia, que cerca os MCs no curto espaço destinado à apresentação.

A intencionalidade dos primeiros versos, aparentemente sem nenhuma relação com o tema selecionado, é formar a perfeita coincidência de sons, o que é essencial nessa expressão literária e nos improvisos, habitualmente. Dessa forma, a análise do "texto" não pode, sob pena de desconstruí-lo, ser realizada tomando-se o verso isolado. No contexto da elaboração poética, os versos iniciais justificam-se, cumprem uma finalidade estética - formada por assonâncias e aliterações - que é um valor muito prezado na literatura oral.

\footnotetext{
${ }^{8}$ Amarildo era um pedreiro que morava na favela da Rocinha e desapareceu em 2013, depois de ter sido preso pela UPP local. Os principais suspeitos da morte do pedreiro são policiais.
} 
QUADRO 2 - Transcrição de rimas de MC Lodk durante a batalha temática, no Museu de Arte do Rio (2015)

\begin{tabular}{|l|l|}
\hline \multicolumn{1}{|c|}{ Versos } & \multicolumn{1}{c|}{ Expressão corporal } \\
\hline O meu carro tá andando. & $\begin{array}{l}\text { Lodk balança o braço para cima e para baixo, } \\
\text { aproxima-se da plateia e pede energia aos } \\
\text { presentes, que, então, gritam, respondendo aos } \\
\text { apelos do MC. }\end{array}$ \\
\hline Ele nunca enguiça. & - \\
\hline O Amarildo não aparece, & $\begin{array}{l}\text { O MC está muito próximo à plateia, quase tocando-a. } \\
\text { Ele anda de um lado para o outro, em passos largos } \\
\text { e balançando o braço desimpedido. }\end{array}$ \\
\hline não aparece a justiça; & $\begin{array}{l}\text { O público anima-se com a performance e balança os } \\
\text { braços, grita, filma, fotografa. }\end{array}$ \\
\hline Agora eu pergunto, & $\begin{array}{l}\text { Vira-se para a plateia, solicitando-a com o braço } \\
\text { livre. Altera o tom de voz, tornando-o mais grave. }\end{array}$ \\
\hline eu não sou infeliz, & $\begin{array}{l}\text { Ele bate com a mão no peito, em atitude que indica } \\
\text { fúria, como se estivesse exigindo uma resposta. }\end{array}$ \\
\hline Cadê o Amarildo & $\begin{array}{l}\text { Com a voz grave e expressão facial sisuda, ele } \\
\text { finaliza esta sequência de forma muito semelhante a } \\
\text { quem se estressa em meio a um debate, } \\
\text { abandonando-o. }\end{array}$ \\
\hline e a justiça do meu país? & \begin{tabular}{l} 
O público grita: "Wow!" \\
\hline
\end{tabular} \\
\hline
\end{tabular}

Dessa forma, "enguiça" é um estratagema para o poeta exigir "justiça", tema-alvo de sua composição e que, no decorrer do texto, tornase evidente. Diferentemente, ocorre com o uso da palavra "infeliz" que rima com "país". Aquela é ali utilizada com uma acepção menos comum. $\mathrm{O}$ contexto - e nisso incluo as ações performativas do MC - aponta que "infeliz" seria o sujeito sem direito à resposta da justiça, aquele que não é cidadão. E o rimador, cônscio de seus direitos, reivindica respeito.

Zumthor, refletindo sobre a oralidade, explica: "Os julgamentos de valor que essa palavra suscita, se fundamentam nas qualidades da voz, na técnica vocal do recitante ou do cantor, tanto ou mais que no conteúdo da mensagem, confirmando o que se sabe" (2010, p. 181).

Entendendo essa poesia oral como performance, que o crítico suíço tão bem iluminou em seus estudos, a expressão literária engendrada pelos MCs é complexa e vem atualizar a literatura urbana carioca. Não cabe na classificação literatura marginal, tal e qual a escola paulista se configura. Porém, uma vez que é realizada por sujeitos em sua maioria periferizados, digo, sem lugar de fala na sociedade, moradores do subúrbio e desconsiderados como artistas pelas instâncias legitimadoras 
da arte e pelos aparelhos de repressão do Estado, é uma voz que encontra acolhida em diversos segmentos sociais e culturais marginalizados.

Com fins de ilustração, o quadro 3 traz um trecho de mais uma produção poética do MC Garcia. O tema é "honestidade". De frente para a plateia, Garcia levanta o braço e convoca o público a levantar a mão, explicando que sabe que todos estão cansados, porque estão em pé, mas diz que o que ele faz - rimar - é com a alma. O MC é extremamente expressivo, sua fisionomia sugere revolta e ele tem o tom de voz bastante elevado.

QUADRO 3 - Transcrição de rimas de MC Garcia durante a batalha temática, no Museu de Arte do Rio (2015)

\begin{tabular}{|l|l|}
\hline \multicolumn{1}{|c|}{ Versos } & \multicolumn{1}{|c|}{ Expressão corporal } \\
\hline $\begin{array}{l}\text { Mas é difícil você falar de honestidade no } \\
\text { Brasil. }\end{array}$ & $\begin{array}{l}\text { O MC balança o braço para cima e para baixo } \\
\text { ininterruptamente, de frente para a plateia. Esse } \\
\text { gesto é firme, veemente. Isso contribui para que seu } \\
\text { discurso de inconformismo seja mais convincente. }\end{array}$ \\
\hline Sabe por quê? Vou explicar a situação. & $\begin{array}{l}\text { A plateia permanece atenta e ansiosa para o } \\
\text { desfecho, isto é, o modo como o rimador } \\
\text { contextualizará a palavra "honestidade". }\end{array}$ \\
\hline $\begin{array}{l}\text { Num país onde valorizam o futebol e } \\
\text { desviam dinheiro da educação. }\end{array}$ & - \\
\hline $\begin{array}{l}\text { "Cê" já parou pra pensar quanto dinheiro } \\
\text { já foi investido }\end{array}$ & - \\
\hline Em obras, mal concedido? & A plateia grita: "Wow!" \\
\hline
\end{tabular}

A rima-denúncia do $\mathrm{MC}$ é a voz da plateia que, não tendo habilidade para a rima, sente-se contemplada com o manifesto do rimador. Por isso, a apreensão do público quanto à finalização do poema. Assim, ainda, justificam-se os gritos de alegria, ao fim da rima.

Antonio Candido, em "A literatura na evolução de uma comunidade" (2006, p. 147), diz que: "Se não existe literatura paulista, gaúcha ou pernambucana, há sem dúvida uma literatura brasileira manifestando-se de modo diferente nos estados". E a modalidade oral de poesia, aqui examinada, encontra nessa afirmação um lugar seu. É uma potente modalidade discursiva que está criando uma enorme teia de rimadores que atuam nas rodas culturais e batalhas de rima, são seguidos por centenas de pessoas nas redes sociais, formam torcidas (sobretudo marcadas pelos territórios de origem) nas disputas e têm suas performances revividas na internet. 
É ainda Candido (2006, p. 155) que, ao refletir sobre a importância da Faculdade de Direito para a literatura de São Paulo, observa: "a convivência acadêmica propiciou em São Paulo a formação de agrupamentos, caracterizados por ideias estéticas, manifestações literárias e atitudes, dando lugar a expressões originais." De modo análogo, afirma-se a importância das rodas culturais e, dentro delas, das rodas e batalhas de rima como inestimável organização para fomentar uma expressão literária da juventude carioca.

Os MCs e outros artistas das ruas carregam uma aura - autoridade, tradição, no sentido benjaminiano. Não que se comportem de modo distinto do público - afinal, eventualmente, também compõem o público -, mas sobre eles recai determinado reconhecimento de uma genialidade que em nada se parece a dos autores canônicos, mas a de alguém que tem um dom especial para organizar as palavras e suas sonoridades. Os MCs circulam com muita liberdade por entre o público, inclusive a inexistência de palco e camarim favorece o contato com o auditório. Entretanto, sabese que ali não é um participante comum do evento: ali está um mestre de cerimônia e, como tal, em algum momento, ele pode tecer uma rima perfeita, ganhar uma disputa, declamar um poema.

A noção de literariedade se aplica à poesia oral? O termo é indiferente: eu defendo a ideia de que existe um discurso marcado, socialmente reconhecível como tal, de modo imediato. A despeito de uma certa tendência atual, descarto o critério de qualidade, devido à sua grande imprecisão. É poesia, é literatura, o que é público leitores ou ouvintes - recebe como tal, percebendo uma intenção não exclusivamente pragmática: o poema, com efeito (ou de forma geral, o texto literário), é sentido como a maior manifestação particular, em um dado tempo e em dado lugar, de um amplo discurso constituindo globalmente um tropo dos discursos usuais proferidos no meio do grupo social (Zumthor, 2010, p. 39).

Esse gênio criativo, então, embora ainda ponha o MC num lugar a que nem todos têm acesso, também não se caracteriza por um talento extraordinário. A notabilidade que o MC carrega não o distancia dos demais. É como se ele pudesse vestir e despir-se da aura em diversos momentos.

Assim, a roda cultural configura-se como um espaço de representação para os jovens identificados com o movimento hip-hop. O MC que rima é o mesmo que minutos antes e depois circula entre as 
pessoas, mora ao lado daquele que o aplaude, trabalha e estuda nos mesmos locais em que os que lá estão. Apresenta-se com vestimentas simples, normalmente de chinelo e mochila nas costas; desloca-se em transporte público, como o público. E essa situação leva centenas de jovens, que nunca se perceberam com talento artístico, a se aventurarem, rimando, cantando, declamando.

A roda cultural é uma oficina e, quanto mais local - ou seja, quanto maior a frequência de moradores do bairro, amigos, família -, maior a chance de o menino da plateia enfrentar o microfone. A presença de mulheres é grande, porém, raramente uma delas encoraja-se a participar do jogo das rimas, pois a participação feminina ainda encontra muita resistência nessa manifestação cultural. As pequenas rodas de rima que se formam espalhadas pelo local onde acontece a roda cultural são excelentes formas de um MC iniciar-se, tendo em vista o número de ouvintes ser bem menor do que quando há uma batalha, momento em que todos praticamente param suas atividades para assistir à competição. Na roda de rima, ele pode errar, falhar, desistir, sem ser cobrado, o que não acontece em uma batalha de rima onde, por mais delicada que seja a plateia, sempre ocorrem comentários, ruídos que denunciam o sentimento dos que estão assistindo.

Se as ruas se abrem como equipamento cultural democrático, instigante, inventivo para novos artistas e formas de artes, ela é também um fator, talvez o mais decisivo, para a criminalização da arte urbana. A festa na rua recebe convidados de tipos mais diversos e que muitas vezes não entendem a gramática do movimento cultural, que reivindicam o estatuto de liberdade do espaço público ou que não permitem ter o comportamento normatizado por produtores culturais, porque estão na rua. Como ensina João do Rio (2008, p. 44): “Desde os mais tenros anos [a rua] resume para o homem todos os ideais, os mais confusos, os mais antagônicos, os mais estranhos, desde a noção de liberdade e de difamação - ideias gerais - até a aspiração de dinheiro, de alegria e de amor, ideias particulares".

É muito comum, assim, que essas manifestações culturais sejam embargadas pelos órgãos públicos - invariavelmente, a polícia -, que atribuem ao organizador da festa uma função que é da instituição policial, ou seja, coibir o consumo de drogas e de venda de bebidas alcoólicas a menores. Don Allan Marola, organizador da Roda Cultural do Méier, desabafa no Facebook: 
Paralisação de "Rodas Culturais" por haverem usuários de drogas em espaços que ocupamos por serem públicos é foda! Não é nosso dever cuidar de que fuma ou de quem bebe. Nosso dever é com a cultura. Nosso dever é passar informação. Nosso dever é tornar um espaço que era abandonado em um lugar agradável e comum a todos. Nosso dever é tornar conhecidos artistas que nunca tiveram a oportunidade de mostrar o que sabem, exibir seu talento para que um possível contato profissional possa acontecer. O que fazemos nada mais é do que promover uma network com os novos talentos e velhos admiradores da arte e produtores. ${ }^{9}$

Elevados decibéis também vêm se juntar aos demais elementos argumentados pelos setores de repressão. Mas isso é facilmente regulável, bastando que a produção do evento disponha-se a reduzir o volume. Muito diferentemente ocorre com o trato com o público (e aqui incluo os vendedores ambulantes), o que está totalmente fora da atribuição da organização do movimento cultural. Ora, sendo a rua o espaço público a que todos têm direito, não causa estranheza que ali se observem os comportamentos mais exóticos, tomando-se, como referência, uma padronização imposta pelas leis. Afinal: “A rua é o local de individualizações, de luta e de malandragem" (DaMatta, 1997, p. 55).

O impasse que se estabelece com essa marginalização deixa os organizadores e a própria manifestação cultural em lugar de fragilidade. Para que rodas culturais, batalhas de rima e outros eventos de arte urbana ocorram, além de todo um percurso burocrático a ser cumprido - como o acesso a declarações e certidões de órgãos públicos -, é necessário que não haja irregularidades aos olhos da polícia que porventura fiscalize o local.

O problema se agrava porque são inerentes à ideologia da arte urbana a liberdade, a defesa da maconha e a autonomia da arte. Quase nenhum organizador de arte de rua consegue ficar isento de providenciar as documentações. E ainda se veem obrigados a responder por atos do público que, como mencionado anteriormente, sente-se livre na rua, acreditando poder agir sem ser incomodado pela imposição de regras. Esse tipo de situação ocorre com frequência em função da proposta dessas festas. E, assim, os organizadores ficam em um dilema:

${ }^{9}$ Disponível em: <https://goo.gl/Sk3vrw〉. Acesso em: 21 maio 2015. 
como seguir com a movimentação cultural, dentro dos conformes da lei, sem cercear o direito de parte do público?

A forma que muitos encontram, mas que está longe de ser uma solução, é investir em campanhas nas redes sociais para que o público não use drogas, para que não sejam vendidas bebidas proibidas a menores. Isso atenua o problema, porém não impede que os jovens socializem da forma como lhes convêm. E mais: desperta críticas por grande parte do público, que vê no movimento cultural um aliado na defesa da liberação da maconha. Em conversa informal, um produtor cultural me disse: "Poxa, meu apelido é Marola. Como chegar para o público e pedir para não fumar maconha? Mas na roda não pode!" Assim, uma pauta cara a movimentos sociais e culturais, a defesa da descriminalização da droga, cria certo embaraço aos produtores da arte de rua.

Outro obstáculo que se coloca é com relação à pichação. Tal arte tem grande apreço dentro dos movimentos urbanos; os pichadores formam uma das tribos juvenis que mais participam das festas de rua. Organizados como poucos grupos culturais, os pichadores reúnem-se com frequência para apresentar seus feitos pela cidade, discutir problemas, prisões, código de ética. E muitas reuniões, ou "reús" como eles denominam, acontecem no mesmo lugar e momento das rodas culturais. Motivo suficiente para atrair a polícia e instaurar-se a discórdia entre organizadores, artistas e público.

Estou investigando micro e macro formas de silenciamentos das rimas das ruas, porque a cada vez que uma roda cultural, batalha de rima ou um espaço para a arte urbana é proibido, são MCs que deixam de trabalhar, são rimas perdidas, é a literatura urbana que se vê calada, marginalizada. Nesse sentido, Gordo Soldados da Pista, organizador da Roda Cultural de São Gonçalo, declara:

Esta semana não vamos ligar o som, porque o Secretário de Postura esteve aqui, passou nas barracas, bares - um tipo de choque de ordem. E tinha uma galera bebendo e fumando na roda. Como não tem segurança, tem droga e álcool sendo vendido para menor. Mas nosso ofício é produzir cultura, não dá pra controlar. Então, o secretário perguntou se eu tinha autorização para a roda. Como eu não tinha, ele mandou cancelar o som. ${ }^{10}$

\footnotetext{
${ }^{10}$ Informação verbal obtida por meio de entrevista concedida à autora deste artigo, em 7 de agosto de 2013, na Roda Cultural de São Gonçalo.
} 
Tratando mais especificamente do objeto em analise aqui, a literatura das ruas, verifica-se, então, que é uma arte marcada, ao menos, por duas formas severas de preconceito: por ser oral, já que a escrita ocupa lugar de relevância em nossa cultura; e por realizar-se na rua.

Taças para cima comemoram a liberdade Sonho de rua virou realidade

Cacife Clandestino ${ }^{11}$

Se, por um lado, a rua é marcada como lugar de incertezas, desmandos, violência, por outro, também é o espaço das surpresas, reinvenções. E, há certo tempo, está muito evidente no comportamento de alguns produtores de cultura urbana uma disposição para que a arte de rua torne-se mais profissional. Embora o uso desse termo pareça em desacordo com a cultura urbana, não creio haver outro mais apropriado, já que o que se percebe são ações com o objetivo de organizar o evento, tornando-o mais atraente para os que já o cultuam, os que não têm o hábito de acompanhar festas nas ruas e também para se resguardar da fiscalização dos órgãos públicos. Em uma publicação em sua página do Facebook, os organizadores da Roda de Rima de Volta Redonda declaram:

A roda continua viva e acesa, e estamos num recesso correndo atrás das devidas regulamentações para o funcionamento total, e ajustando os ponteiros para voltar ainda mais forte, com ideias novas e novos desafios e uma nova proposta mais exata, onde o objetivo é a difusão do rap através de uma maneira positiva e didática. ${ }^{12}$

Dessa forma, além de ter de providenciar documentos obrigatórios, de buscar artistas mais cultuados e de promover atrações mais variadas, os organizadores sentem necessidade de compreender como funciona a máquina burocrática da cidade, além de conhecer os setores e profissionais que podem ajudá-los a ocupar as ruas da cidade sem sobressaltos. Essa pauta é nova e instigante. Sobretudo porque, ligada ou não ao movimento hip-hop - e aqui em evidência estão dois objetos com estreita relação com o hip-hop -, a arte de rua propõe-se autônoma. E esse esforço de buscar apoio, isto é, autorização do poder público, é comumente percebido como subserviência ao "opressor". Por isso,

\footnotetext{
${ }^{11}$ Versos da música "Sonho de rua". Disponível em: $<$ https://goo.gl/lDKSbM>.

${ }^{12}$ Disponível em: <https://goo.gl/qRP0As>. Acesso em: 3 ago. 2015.
} 
apossar-se de um conjunto de medidas burocráticas, embora imprescindível, é também motivo de ironias, xingamentos, críticas nas redes sociais por parte de grupos mais intransigentes.

Há grupos que ainda creem que seja possível a sobrevivência dessa manifestação cultural sem algum tipo de agenciamento público. E mais: que sendo avalizada pelo poder público, a ação cultural perde sua identidade. Acreditam e defendem uma identidade "pura". Ou seja, a noção de identidade como "celebração móvel" (Hall, 2003) não encontra respaldo entre inúmeros artistas do hip-hop. Não se tem ainda bem matizado entre os artistas e produtores culturais a noção de cultura como processo. Muitos defendem que hip-hop bom é aquele do início do movimento no Brasil; fala-se em "essência", em momento áureo, em que as composições e ideologias não compactuavam com o sistema político-econômico.

Entretanto, o que essa aproximação com a máquina pública está evidenciando é que os atores da arte de rua, ao estudarem estatutos e leis, participarem de editais públicos e recorrerem às instâncias responsáveis pela ordem pública, estão se empoderando.

O termo empoderamento, embora não seja possível precisar seu surgimento, teve seu uso disseminado a partir dos movimentos black e feministas, nos anos 1970. Em sua acepção mais simples, empoderar é dar poder, capacitar.

A respeito do poder, Foucault diz:

Se o poder fosse somente repressivo, se não fizesse outra coisa a não ser dizer não você acredita que seria obedecido? O que faz com que o poder se mantenha e seja aceito é simplesmente que ele não só pesa como uma força que diz não, mas que de fato ele permeia, produz coisas, induz ao prazer, forma saber, produz discurso $(1979$, p. 8).

Na manifestação cultural em tela, a capacitação e o poder vêm sendo identificados, de modo mais explícito, nas condutas de enfrentamento de uma situação que por longo tempo foi paralisante. A poesia do gênero rep, combativa e pedagógica, é mais um dispositivo eficientíssimo - no embate por um lugar de ação. Porém, com um acesso restrito, mesmo inacessível, entre as esferas de poder, entendidas aqui como as instituições de repressão. Assim, o empoderamento dos grupos de arte urbana tem se tornado mais efetivo, dando-se numa esfera da qual sempre estiveram ausentes: os órgãos públicos de ordenamento da 
cidade, a Assembleia Legislativa, a Câmara de Vereadores, o Gabinete do Prefeito, entre outras secretarias de governo.

Essa instrumentalização para disputar o direito à rua, muito aquém de indicar um servilismo aos poderes públicos, tem capacitado melhor os produtores culturais e artistas para o enfrentamento com os aparelhos públicos da burocracia. "Onde há poder há resistência [...]. E não é uma relação unívoca, unilateral; nessa disputa ou se ganha ou se perde" (Machado, 1979, p. 171). Assim, resistir é atuar nos interstícios. A arte urbana vive um instante embaraçoso e promissor.

O que é teoricamente inovador e politicamente crucial é a necessidade de passar além das narrativas de subjetividades originárias e iniciais e de focalizar aqueles momentos ou processos que são produzidos na articulação de diferenças culturais. Esses "entre-lugares" fornecem o terreno para a elaboração de estratégias de subjetivação - singular ou coletiva - que dão início a novos signos de identidade e postos inovadores de colaboração e contestação, no ato de definir a própria ideia de sociedade (Bhabha, 1998, p. 20).

Apesar de ainda ser objeto de aversão, esse envolvimento com a coisa pública não tem se dado apenas no intuito de obter atestados para o funcionamento da manifestação cultural, mas há também significativo interesse por editais de fomento à cultura. Dentro dessa perspectiva, dois editais lançados em 2014 são essenciais para compreender de forma mais amiúde a parceria que está se realizando entre esferas comumente tão distantes - arte de rua e poder público. São eles o Prêmio Cultura Hip Hop, da Funarte; e o Prêmio de Ações Locais, da Secretaria Municipal de Cultura do Rio de Janeiro.

Ressalte-se que os editais desses prêmios, com suas delimitações, respondem a duas demandas comuns nos meios artísticos e culturais não hegemônicos, que são a desburocratização do processo de inscrição e o desafio de "trazer equipamento e financiamento para as comunidades sem tutelá-las, sem impor um modelo organizacional” (Simis, 2007, p. 148).

Entende-se, com atraso, que as políticas públicas para a cultura existem para o cidadão, que disputá-las é um direito e que receber verba para aprimorar uma arte que se realiza com base em parcos ou nenhum recurso financeiro não pode ser lido como apoio ao governo ou chancela a toda e qualquer política pública. Antes, é uma forma de disputar cidadania, considerando-se que política pública compreende: 
escolha de diretrizes gerais, que têm uma ação e estão direcionadas para o futuro, cuja responsabilidade é predominantemente de órgãos governamentais, os quais agem almejando o alcance do interesse público pelos melhores meios possíveis, que no nosso campo é a difusão e o acesso à cultura pelo cidadão (Simis, 2007, p. 133).

O Prêmio Cultura Hip Hop, por dirigir-se explicitamente a proponentes que trabalham com o movimento hip-hop e afins, tem uma receptividade menos atribulada nesse meio artístico. Entretanto, causa estranhamento que, dentro de um movimento cultural tão grande, tão poucos ainda optem por esse tipo de fomento: em 2014, entre rodas culturais e batalhas de rima, houve apenas seis inscritos e cinco aprovados. O edital foi dirigido a pessoas físicas, instituições sem fins lucrativos e coletivos sem constituição jurídica, com o propósito de:

divulgar e dar visibilidade às iniciativas culturais do hip hop; incentivar a participação plena e efetiva do atores e protagonistas do hip hop na elaboração e no desenvolvimento de projetos e ações culturais; subsidiar a elaboração de políticas públicas de cultura específicas para o segmento hip hop (Funarte, 2014).

Já o Prêmio de Ações Locais, de alcance apenas municipal, abriu-se para ações culturais de vertentes variadas, não se dirigindo a um gênero artístico específico:

entende-se por ação local a realização continuada de práticas, atividades e projetos nos campos da cultura, arte, comunicação e do conhecimento que promovam transformações socioculturais positivas nas comunidades e nos territórios em que são desenvolvidos; as ações locais deverão fomentar o exercício da cidadania e fomentar a diversidade da cultura carioca, nas suas expressões populares, urbanas e tradicionais. (Rio de Janeiro, 2014).

Ainda assim, apesar da estratégia de marketing muito bem elaborada e do auxílio de "articuladores locais" - produtores culturais que iam em busca de movimentos culturais, apresentando e auxiliando no preenchimento do edital -, não houve significativa procura por parte de rodas culturais e batalhas de rima.

Considerando-se as dezenas de rodas culturais e batalhas de rima existentes, o número total de proponentes dessas vertentes foi bem baixo: entre rodas culturais e batalhas de rima, houve dez inscritos, dos quais seis foram classificados, três chancelados e um inabilitado. 
Entretanto, sabendo-se que os atores desse tipo de ação são arredios a tais formas de fomento e políticas públicas para a cultura, foi com admiração que recebi os números de participações nesses editais. O depoimento de Rafaela Elisiario, organizadora da Roda Cultural do CDC - Petrópolis, explicita a pouca habilidade para o trato com a burocracia: "A gente ficava de cabelo em pé com a burocracia dos editais e projetos. Você tem que ir a vinte órgãos da cidade antes de fazer um festival e fica esperando um liberar para ir no outro. E o outro demora, porque não entende o movimento."13

Esses editais constituem excelentes meios de promoção da arte urbana, pois muito além da ajuda financeira - nada desprezível -, os produtores de arte de rua vêm utilizando esses mios para obterem outras vantagens, como negociar com os órgãos públicos, quando da interdição ou outros impedimentos das rodas e batalhas. Assim aconteceu com a Roda Cultural de Olaria, que acontece numa quadra pública, no bairro de Olaria, subúrbio do Rio de Janeiro, e recebeu multa da Inspetoria Regional de Licenciamento e Fiscalização no valor de R \$ 680,09.14

Os organizadores da roda, então, foram à subprefeitura contestar a multa, e utilizaram o fato de terem sido aprovados no Prêmio de Ações Locais como um dos argumentos à favor da realização da manifestação cultural. E, ainda, seguindo a mesma linha argumentativa, o Circuito Carioca de Ritmo e Poesia (CCRP) publicou, nas redes sociais, uma cartamanifesto, revelando a indignação com relação à proibição de tantas rodas culturais. Com o título "Reconhecidas, premiadas e proibidas", 15 o coletivo apontava as contradições de uma prefeitura que lança um edital de apoio às manifestações culturais de grupos marginalizados, ao passo em que reprime essas mesmas manifestações. Indo além, o CCRP citava o Decreto $\mathrm{n}^{\mathrm{o}} 36.201$, de 6 de setembro de 2012, em que o prefeito reconhece as rodas culturais do CCRP como movimento cultural da cidade do Rio de Janeiro, enquanto os órgãos públicos da mesma prefeitura perseguem-nas.

Já foi apresentada aqui a fala do organizador da Roda Cultural de São Gonçalo. Essa roda é qualificada por integrantes dos movimentos de rua

\footnotetext{
${ }^{13}$ Informação verbal obtida em entrevista concedida à autora deste artigo, em janeiro de 2015, na Roda Cultural de Petrópolis.

${ }^{14}$ Informação publicada na página da roda no Facebook. Disponível em: 〈https://goo.g1/D5uB5O〉. Acesso em: 19 jun. 2015.

${ }^{15} \mathrm{O}$ texto foi publicado na página do CCRP no Facebook. Disponível em: <https://goo.gl/aJcH1h〉. Acesso em: 26 jun. 2015.
} 
como "resistência", porque invariavelmente se vê impedida de se realizar. E, no entanto, o produtor cultural, Gordo Soldados da Pista, insiste em manter o movimento. Em dezembro de 2014, a polícia esteve no local da roda e reprimiu violentamente o movimento, destruindo som, usando spray de pimenta, entre outras arbitrariedades. ${ }^{16}$ Entretanto, os artistas e frequentadores voltaram nas semanas seguintes e fizeram uma manifestação sem som, à capela, registrando a manifestação em vídeo, posteriormente disponibilizado no Youtube. Nesses encontros, MCs produziram rimas que tematizavam a situação que estavam vivendo, como nesses versos do MC FP: "Não sou como esses filhos da puta que chegam com marra pra acabar com a cultura/Com a cultura, meu mano, não tem caô, não vem esculachar trabalhador/Tá ligado, parceiro, eles sobem lá na viela, pra tocar terror na nossa favela/ Tá ligado? É tudo farsa. Eles vêm aqui pra foder com a nossa praça."17

A poesia não esteve calada; ao contrário, a repressão impulsionou uma construção discursiva mais crítica, e a roda cultural fez justiça à sua fama de "resistência". Nesse episódio, não apenas a truculência da polícia e a poesia "revoltada" notabilizaram-se, mas também as formas que essa roda cultural utilizou para reverter a situação de marginalização em que vivia.

A estratégia mais imediata e impactante foi a publicação dos vídeos com a ação da polícia nas redes sociais e na plataforma Youtube, o que gerou inúmeras visualizações, compartilhamentos, protestos e mensagens de apoio. Mesmo pessoas sem afinidade com o movimento sensibilizaram-se com as cenas.

Assim, em nota de repúdio à ação da polícia militar, postada pela Roda Cultural de São Gonçalo em sua página na rede social Facebook, soubemos da truculência da polícia: quebrando equipamentos de som, barracas de ambulantes, lançando spray de pimenta, sem nenhuma tentativa de diálogo com produtores e público. Os vídeos e relatos (de fácil acesso na plataforma Youtube) confirmam a opressão. ${ }^{18}$ A Roda Cultural de São Gonçalo ganhou, com essa estratégia, a simpatia e adesão de centenas de pessoas.

\footnotetext{
${ }^{16}$ Ver vídeo publicado no Youtube, em que os frequentadores manifestam sua indignação com o ocorrido. Disponível em: 〈https://goo.gl/AagIwF>.

${ }^{17}$ Disponível em: <https://goo.gl/eOGgu3>. Acesso em: 20 jun. 2015.

${ }^{18}$ Disponível em: <https://goo.gl/9iHPVD>. Acesso em: $11 \mathrm{dez} .2014$.
} 
O organizador da roda em evidência sempre demonstrou desprezo pela burocracia. Dizendo-se artista, alegava que sua função era organizar e apresentar as atrações, sem se envolver com as complicadas e cansativas questões administrativas. Porém, após o episódio de excesso promovido pela polícia, ele procurou a Secretaria de Cultura do município, conseguindo alvará para realização do evento. E, novamente, as redes sociais foram escolhidas, porém, para outra forma de manifestação agora de admiração e legitimação à Secretaria de Cultura. Gordo Soldados da Pista, o produtor cultural da roda, expressou no Facebook sua satisfação e entusiasmo quanto à reunião que tivera com o secretário de Cultura, Michel Portugal: "Tenho orgulho em dizer que a Sec. de Cultura é hip-hop". No encontro, o secretário comprometeu-se a regularizar a roda, respaldando-a contra iniciativas que tentassem criminalizar o movimento, com um documento oficial da prefeitura: “Esse documento em minhas mãos nos dá independência para continuar nosso movimento dentro da lei. Obrigado a todos que acreditam na gente, nossa vitória não será por acidente."19

Importante momento, então, em que se vislumbram outras possibilidades de diálogo entre políticas públicas - de segurança, de cultura - e a cultura de rua, que não se coloca nessa querela apenas como o lado mais fraco da negociação, mas também como o ator que já pode escolher negociar ou não e impor certas condições. Como Hall (2003) aponta, o que é relevante são as estratégias culturais que conseguem abalar o poder. A luta contra os poderes hegemônicos, indubitavelmente, ainda se desenvolve de maneira bastante desigual; os espaços para a luta cultural são escassos e muito verticalizados. Porém, as novas estratégias adotadas pelos segmentos subalternos não têm como fim ser "o mesmo" e estão produzindo agências. Logo, são meios que não devem ser menosprezados.

\section{Referências}

ALVES, Rôssi (2014). Rimas das ruas. Revista Z, Rio de Janeiro, n. 2. On-line. Disponível em: <http://revistazcultural.pacc.ufrj.br/rimas-das-ruas/>. Acesso em: 21 jul. 2016.

${ }^{19}$ Disponível em: 〈https://goo.gl/Se5fYp〉. Acesso em: 23 fev. 2015. 
BHABHA, Homi (1998). O local da cultura. Tradução de Myriam Ávila, Eliana Reis e Glaucia Gonçalves. Belo Horizonte: Editora da UFMG.

BAKHTIN, Mikhail (1997). Marxismo e filosofia da linguagem: problemas fundamentais do método sociológico na ciência da linguagem. Tradução de Michel Lahud e Yara Frateschi Vieira. 8. ed. São Paulo: Hucitec.

CANDIDO, Antonio (2006). Literatura e sociedade. Rio de Janeiro: Ouro Sobre Azul.

DAMATTA, Roberto (1997). A casa e a rua: espaço, cidadania, mulher e morte no Brasil. Rio de Janeiro: Rocco.

FELIX, João Batista (2005). Hip-hop: cultura e política no contexto paulistano. São Paulo. Tese (Doutorado em antropologia social) - Faculdade de Filosofia, Letras e Ciências Humanas da Universidade de São Paulo, São Paulo.

FOUCAULT, Michel (1979). Microfísica do poder. Organização e tradução de Roberto Machado. Rio de Janeiro: Graal.

FUNARTE - FUNDAÇÃO NACIONAL DE ARTES (2014). Edital Prêmio Cultura Hip Hop 2014. Rio de Janeiro, 25 ago. Disponível em: <http://goo.gl/g3bENy>. Acesso em: 21 jul. 2016.

HALL, Stuart (2003). Da diáspora: identidades e meditações culturais. Organização de Liv Sovik. Traução de Adelaine Resende, Ana Carolina Escoteguy, Claudia Álvares, Francisco Rudiger, Sayonara Amaral. Belo Horizonte: Editora da UFMG.

MACHADO, Roberto (2006). Foucault: a ciência e o saber. 3. ed. ver. e ampl. Rio de Janeiro: Jorge Zahar.

RIO, João do. (2008). A alma encantadora das ruas. São Paulo: Companhia das Letras.

RIO DE JANEIRO (Município) (2012). Decreto $n^{\circ} 36.201$, de 6 de setembro de 2012. Dispõe sobre o Programa de Desenvolvimento Cultural Carioca de Ritmo e Poesia. Diário Oficial do Município do Rio de Janeiro, Rio de Janeiro, n. 120, p. 6, 10 set. Disponível em: <http:/ /goo.gl/Cm4jYX>. Acesso em: 21 jul. 2016.

RIO DE JANEIRO (Município) (2014). Secretaria Municipal de Cultura. Prêmio de Ações Locais - Edição Rio450. Rio de Janeiro, 16 out. Disponível em: <http://goo.gl/c74BJb>. Acesso em: 21 jul. 2016.

SIMIS, Anita (2007). A política cultural como política pública. In: SIMIS, Anita.(Org). Políticas culturais no Brasil. Salvador: Edufba, p.133-155. 
ZUMTHOR, Paul (2010). Introdução à poesia oral. Tradução de Jerusa Pires Ferreira, Maria Lucia Diniz Pochat e Maria Ines de Almeida. Belo Horizonte: Editora da UFMG.

Recebido em outubro de 2015.

Aprovado em março de 2016.

\section{resumo/abstract/resumen}

\section{Resistência e empoderamento na literatura urbana carioca}

\section{Rôssi Alves}

No estado do Rio de Janeiro, a ocupação do espaço público por coletivos de arte e cultura tem trazido inovadoras contribuições às linguagens artísticas. Trocas, hibridismos, experimentações de manifestações culturais variadas encontram nas ruas e praças um lugar de acolhimento. Este artigo tratará de uma forma de ocupação, a Roda Cultural, que, indo além da função de levar arte para o espaço público, propicia a produção de uma expressão literária singular - as rimas das ruas. No entanto, dado que o espaço público é regulado e disputado por segmentos diversos, a ocupação geralmente é marcada por tensões, as quais, por longo tempo, paralisavam os atores da arte de rua, que não acreditavam na possibilidade de uma negociação com os poderes públicos. Entretanto, com o acirramento da repressão e a necessidade cada vez maior de outras formas de lazer e cultura públicos, os agentes envolvidos nesta cena vêm envidando esforços no sentido de uma articulação com os órgãos responsáveis pelo ordenamento urbano, e estes, por sua vez, têm buscado promover alguns movimentos de maior visibilidade, como forma de terem suas políticas de cultura chanceladas pela "rua". A arte de rua descobre, a custo, que dialogar e instrumentalizar-se para lidar com a coisa pública é também uma forma de resistência.

Palavras-chave: arte urbana, resistência, políticas públicas, empoderamento.

\section{Resistance and empowerment in urban literature of Rio de Janeiro}

\section{Rôssi Alves}

In the state of Rio de Janeiro the occupation of public areas by art and culture collectives has brought innovative contributions to artistic languages. Exchanges, hybridisms, and experimentations of various cultural manifestations find a welcoming place in streets and public squares. This article will be studying the Roda Cultural in regards to its character as an occupation. This event not only takes art to public areas, but it also uncovers the production of a singular literary expression - 
the streets' rimes. Nevertheless, since the public areas are regulated and disputed by various segments, the occupation is usually marked by tensions. For a long time, these used to paralyze street art actors who did not believe a negotiation with the public powers was possible. However, with the growth in repression and the increasing need of other types of public leisure and culture, agents involved in the scene have incremented their efforts to negotiate with the sectors in charge of urban development, which, in turn, have attempted generate initiatives aimed at incrementing visibility in order to validate its cultural policies through the "streets." Street art is discovering, albeit it with some difficulty, that the interaction and sorting out of the right tools to cope with public powers, is also a way of resistance.

Keywords: urban art, resistance, public policies, empowerment.

\section{Resistencia y empoderamiento en la literatura urbana carioca}

\section{Rôssi Alves}

En el estado de Rio de Janeiro la ocupación del espacio público por colectivos de arte y cultura ha traído contribuciones innovadoras a los lenguajes artísticos. Intercambios, hibridismos, experimentaciones de variadas manifestaciones culturales encuentran en las calles y plazas un lugar de acogida. Este artículo tratará de una forma de ocupación, la Roda Cultural, que yendo más allá de la función de llevar el arte al espacio público, permite la producción de una expresión literaria particular - las rimas de la calle. Sin embargo, dado que el espacio público es regulado y disputado por diversos segmentos, la ocupación es marcada generalmente por tensiones. Éstas solían paralizar a los actores del arte de la calle, que no creían en la posibilidad de negociación con los poderes públicos. Sin embargo, con el aumento de la represión y la necesidad cada vez mayor de otras formas públicas de recreación y cultura, los agentes involucrados en esta escena vienen sumando esfuerzos hacia una articulación con los órganos responsables del planeamento urbano, al mismo tiempo que éstos intentan promover manifestaciones que les den más visibilidad para validar sus políticas culturales en las calles. El arte callejero está descubriendo, no sin dificultad, que dialogar e instrumentalizarse para tratar con la cosa pública también es una forma de resistencia.

Palabras clave: arte urbana, resistência, políticas públicas, empoderamento. 